\title{
Preferential votes and minority representation in open list proportional representation systems
}

\author{
Margherita $\operatorname{Negri}^{1}$ (D
}

Received: 7 December 2016 / Accepted: 5 September 2017 / Published online: 4 October 2017

(C) The Author(s) 2017. This article is an open access publication

\begin{abstract}
Under open list proportional representation, voters vote both for a party and for some candidates within its list (preferential vote). Seats are assigned to parties in proportion to their votes and, within parties, to the candidates obtaining the largest number of preferential votes. The paper examines how the number of candidates voters can vote for affects the representation of minorities in parliaments. I highlight a clear negative relationship between the two. Minorities are proportionally represented in parliament only if voters can cast a limited number of preferential votes. When the number of preferential votes increases, a multiplier effect arises, which disproportionately increases the power of the majority in determining the elected candidates.
\end{abstract}

\section{Introduction}

The label proportional representation (PR) refers to any multi-member district system where seats are assigned to parties in proportion to the share of votes they receive. An important distinction within this class of electoral systems relates to the rules governing seat allocation within parties. Suppose a party running with a list of ten candidates wins four seats in a district: which of the candidates on its list will be elected? In some countries (among many others, Argentina, Israel, Spain and South Africa), seat allocation follows a ranking of candidates that is determined by party leaders before election. In the example, the first four candidates on the party list would be assigned the seat under this system. Voters cannot modify the ranking and can only cast a vote for a party list as a whole. In other countries (e.g. Belgium, The Netherlands or Sweden), voters can affect the ranking decided by parties by casting

Margherita Negri

mn48@st-andrews.ac.uk

1 School of Economics and Finance, University of St Andrews, St Andrews, UK 
a specific vote (a preferential or preference vote) for some candidates within the list. Candidates obtaining enough preferential votes are elected independently of their position on the original ranking. In the example, if, say, the tenth candidate on the list received enough preferential votes, she would be elected in place of one of the first four candidates. Finally, there are countries (e.g. Finland and Brazil) where rankings are solely determined by preferential votes. Under this system, the four seats won by the party in the example would be assigned to the four candidates obtaining the highest number of individual votes. The three systems are known as closed, flexible (or semi-open) and open list PR, respectively. It is important to remark that, under flexible and open list PR, voters can cast a vote both for a party and for some candidates. The party-vote is what differentiates these systems from limited vote.

Preferential votes under open list PR (and, to some extent, under flexible list PR) are equivalent to approval voting within party lists: voters decide to approve (and not rank) some of the politicians appearing on the ballot. Only one approval vote can be cast for each candidate (no cumulative voting). The total number of approval votes that can be expressed can vary a lot from country to country. For example, it is equal to one in Sweden, Finland, Denmark and Brazil, it varies from one to five-depending on the electoral district-in Greece and it coincides with the total number of candidates on the list in Belgium.

This paper investigates the extent to which the interests of minority groups can be protected under open list PR systems. As a measure of representation of minorities, I consider the number of elected candidates representing the group. ${ }^{1}$ If minorities were able to organize themselves into parties, the question would boil down to the analysis of seat allocation across parties. The extent of minority representation would then only depend on the mapping of votes into seats and on the presence (and level) of minimum thresholds for representation. This is the focus of the literature on threshold for representation and threshold for exclusion (among others, Rae et al. 1971; Lijphart and Gibberd 1977; Taagepera 1998). ${ }^{2}$ However, party structures in countries using PR systems might not necessarily represent the minority/majority divide. For example, Huber (2012) shows that the "ethnicization" of voting behavior (i.e. the correlation between voting decisions and individuals' ethnicity) is actually lower under PR than it is under first-past-the-post systems. In other words, ethnic groups often split their votes across different parties and there might not be parties primarily receiving votes from one specific ethnic group. This happens because, "although PR makes it possible for ethnically oriented parties to form, it also makes it easy for non-ethnic parties to compete for ethnic votes". 3 In such a scenario, then, minority candidates might appear on party lists that represent different interests. The rules governing seat allocation within party lists become of key importance to determine the level of minority representation in this context.

\footnotetext{
1 The analysis therefore concerns the formal representation of minorities, as opposed to the substantial representation (Pitkin 1967).

2 The two thresholds represent the minimum amount of votes a party should obtain to win a seat and the maximum amount of votes that would not guarantee the seat to the party, respectively.

3 Huber (2012, p. 999).
} 
The paper considers a society divided in two groups of unequal size, that I call minority and majority. Voters vote under open list PR: they must cast a vote for one out of two parties and assign some preferential votes to candidates within its list. Voters can only approve candidates belonging to the list of the party they voted for and can cast at most one preferential vote per candidate. The seats won by the party are assigned to the candidates in the list who received the largest number of preferential votes. I assume list composition is dictated by the law: lists must contain a share of candidates representing each group equal to the relative size of the group in the population. Furthermore, I make a number of conservative assumptions on voters' characteristics. First, I assume that members of each group are perfectly able to coordinate. This allows to consider a game between two players, the minority and the majority. ${ }^{4}$ A similar degree of coordination is assumed in ethical voters models (Coate and Conlin 2004; Feddersen and Sandroni 2006). Groups preferences are defined on the minority/majority dimension: each group aims at maximizing the number of elected candidates representing its interests. Voters are perfectly able to distinguish minority and majority candidates. Finally, all candidates representing the same group are identical and cannot campaign to attract votes from different groups. ${ }^{5}$ What I am considering is therefore a best-case type of scenario.

Even under this scenario, my results show that minority representation can be very limited under open list PR. In particular, the analysis highlights a clear negative relationship between the number of preferential votes and the number of elected candidates representing the interests of the group. Perfectly proportional representation (a situation where the share of elected minority candidates is equal to the relative size of the group in the population) is guaranteed only if voters can cast a small number of preferential votes.

The intuition behind the negative correlation between number of preferential votes and minority representation is as follows. An important characteristic of open list PR is that candidates are guaranteed to be elected if the number of preferential votes they receive is above a specific threshold. Guaranteed here means that their election is independent of the total number of seats won by their party and the number of preferential votes obtained by other candidates. The threshold turns out to be proportional to the number of preferential votes that can be expressed. When voters can cast few preferential votes, the threshold is low. Then, the votes of the minority are enough to guarantee that (the votes received by) some minority candidates pass the threshold. The larger the number of preferential votes, the lower the ability of the minority to cast enough votes on specific candidates and guarantee their election. Furthermore, an increase in the number of preferential votes produces a "multiplier" effect on the power of the majority. Assume the minority contains two individuals, while the major-

\footnotetext{
4 The pure strategy Nash equilibria of this two-player game are equivalent to Strong Nash equilibria (Aumann 1959) of a game where each voter acts as a different player, when these equilibria exist.

5 A consistent literature has analyzed the difference between candidates' behavior under open list and closed list PR (Carey and Shugart 1995; Chang 2005; Shugart et al. 2005; Chang and Golden 2007; Ames 1995). The main conclusion is that open list PR increases the value of candidates' personal reputation as opposed to party reputation. This happens both because open list enhances intra-party competition and electoral uncertainty (Carey and Shugart 1995; Chang 2005) and because it induces voters to focus more on candidates' characteristics and less on parties' positions (Shugart et al. 2005).
} 
ity contains six. The difference between the total number of preferential votes that can be expressed by the two groups is 4 if each individual can cast one preferential vote, 8 if they can cast two, 12 if three, etc. If the majority equally splits its votes across the two parties, it will be able to give more and more preferential votes to more and more majority candidates, eventually preventing the election of any minority candidate.

Even though ethnic politics versus class politics is a dilemma mostly in developing countries, ${ }^{6}$ a similar dilemma exists in democratizing countries. ${ }^{7}$ Consider a society divided along a class (i.e. income-related) dimension and an ethnic dimension. Suppose that the two parties in my model are the party of the rich and the party of the poor. When the poor of both ethnic groups prefer to channel their frustration through ethnic politics, the relevant coalition is between the rich majority group and the poor majority group, against the rich and poor minority groups. In this case, the scenario is similar to the one I consider in my model. ${ }^{8}$ If the system is open list PR and many preferential votes can be cast, the majority ethnic group will divide up optimally the votes across parties, because its main goal is coordinating to defeat the minority group. Taking a step back and considering the constitutional stage in a democratizing country, these conclusions imply that an ethnic majority group might prefer to choose an open list PR system with a large number of preferential votes. Whenever the ethnic politics cleavage dominates the class cleavage, this system will allow to reduce the representation of the minority group.

In the baseline model, parties are passive players. Given the quota system specified by the law and the assumptions about candidates' characteristics, they essentially can play no role in deciding list composition. This very simplified and stylized scenario constitutes a first step in the analysis of minority representation under open list PR and allows to obtain clear and precise conclusions about the effect of the number of preferential votes. In Sect. 4.1, I briefly discuss the possibility of endogenizing list composition. I assume parties want to maximize the number of seats won and can decide how many minority and majority candidates to include in their lists. Two interesting insights emerge from this extension. First, contrary to what one would expect, the incentives to include minority candidates in the list are weaker when few preferential votes are allowed. Under reasonable assumptions on voting behavior in the subgames, no equilibrium exists where both parties include minority candidates in their lists. In addition, there can be an equilibrium where both parties only contain majority candidates. When voters can cast a large number of preferential votes, these type of equilibria are harder to sustain. Interestingly enough, the primary reason for including minority candidates in the list is not to attract the votes of the minority. Indeed, when the minority votes for a party and many preferential votes can be cast, the majority

\footnotetext{
6 Take for example the comparison between India and Indonesia suggested by Huber (2017): the two countries have a similar level of ethnic diversity, but ethnic politics is much stronger in India than it is in Indonesia. The interaction between economic and ethnic diversity play a crucial role in explaining this difference.

7 For example, ethnic politics played a much more central role in Ukraine than it did in Georgia, despite a similar level of ethnic diversity in the two countries (Huber 2017).

8 Thus, the presence of two different parties in my model implicitly represents a second cleavage in the society. This cleavage becomes secondary when the minority/majority cleavage is particularly strong.
} 
always best responds by voting for that party too. The number of votes assigned to the party by the group is strictly greater than the number of voters in the minority. In this way, some majority candidates in the party receive an amount of preferential votes that is strictly larger than the one received by any minority candidate, gaining priority in the allocation of seats (the larger the amount of preferential votes that can be expressed, the larger the number of such candidates and the lower the number of elected minority ones). By including minority candidates in their lists, then, parties are able to attract a consistent amount of votes by the majority.

The discussion in Sect. 4.1 confirms how the main analysis in the paper is conducted under a best-case scenario for the minority. When list composition is dictated by the law, the group can be represented in parliament only if the number of preferential votes that can be expressed is small enough. In this case, however, parties have very low incentives to actually include minority candidates in their lists. Overall, this strengthens the conclusion that minority interests can be poorly protected under open list PR. The results suggest that the best way to achieve perfect minority representation is to limit the number of preferential votes that can be expressed and impose a system of quotas on party lists.

A second important insight of Sect. 4.1 is that, if parties care about maximizing the number of seats won, a situation in which only one party contains minority candidates (or, in other words, the existence of a "minority party") is unlikely to occur. Whenever only one party contains minority candidates in its list, two possible incentives can arise. First, the party might be tempted to replace the minority candidates with majority ones to attract more votes by the majority. Second, the other party might be induced to include minority candidates in its list too. When few preferential votes can be expressed, both incentives can arise, depending on the specific assumptions one makes about equilibria in the voting subgames. Equilibria with "minority parties" exist only under very specific assumptions. When the number of preferential votes is large, only the second effect arises.

As noted above, by assuming a cohesive minority behavior I am stacking the deck against the results I obtain in the model. My results show that, even if the minority is perfectly able to coordinate, open list PR can be associated with very limited minority representation. Clearly, reducing the coordination power of the minority would only strengthen this conclusion. On the other hand, reducing the coordination power of the majority would probably result in higher minority representation. However, for a fixed degree of coordination ability, the comparative statics on the effect of the number of preferential votes would persist. The chances of electing a minority candidate in a party decrease when (i) enough majority voters vote for that party and (ii) they give enough preferential votes to their favorite candidates. Limiting the coordination ability of the majority would affect both components. However, for a given probability that enough majority voters vote for a party, an increase in the number of preferential votes definitely increases the number of majority candidates obtaining a consistent amount of votes. This reduces overall minority representation. Section 6.1 further discusses this intuition and provides an illustrative example.

The negative correlation between minority representation and the number of preferential votes had already been established for limited vote systems (Lijphart et al. 1986). In these systems, all candidates appear on the same ballot, voters do not cast 
a vote for parties and can only express preferential votes for candidates. The elected candidates are those who received the largest number of votes. Open list PR therefore differs from limited vote because of the possibility to cast a vote for a party list. The importance of my contribution with respect to the literature on limited vote stems from two observations. The first is more practical. Open list PR is a much more widely used electoral system than limited vote. ${ }^{9}$ Establishing how well minority interests are protected under this system is therefore of great relevance. The second observation is more technical: the presence of a party-vote in open list PR is a relevant difference with respect to limited vote. Two effects come into play. First, while under limited vote a candidate competes with all the other candidates, under open list PR she primarily competes with the subset of politicians on the same party list. Most importantly, the election of a minority candidate in a party is independent of the number of votes received by candidates in the other party. This limits the power of the majority to reduce minority representation: while under limited vote it is enough to assign enough votes to many majority candidates, under open list PR the group must assign enough votes to many candidates in both parties. The second effect arises from party behavior. Under open list PR, parties have stronger incentives to include minority candidates in their lists. The intuition is explained in Sect. 5 with the help of an example. The two effects combined imply a (relatively) better performance of open list PR in protecting minority interests.

The remainder of the paper is organized as follows. Section 2 introduces the model. Section 3 contains the results. Section 4 extends the analysis to endogenous list formation and larger number of parties. This is followed by a comparison between open list PR and limited vote (Sect. 5). Section 6 discusses the assumption of perfect coordination and provides an example about class- versus ethnic-identity. Section 7 concludes. All proofs can be found in the Appendix.

\section{The model}

Consider a country whose total voting population is $V$. Voters are divided in two groups: a minority, $m$, and a majority, $M$. Let $V_{j}$ denote the number of voters in each group $j \in\{m, M\}$, with $V_{m}<V / 2$ and $V_{m}+V_{M}=V$. During an election, voters must choose $S$ representatives in a unique electoral district. There are $2 S$ candidates, equally divided in two party lists, $A$ and $B$. I assume the law requires each list to contain candidates representing both groups, in proportion to the size of the group in the population. For simplicity, I set $V=S$, so that each list must contain $V_{m}$ minority candidates and $V_{M}$ majority candidates (I discuss this assumption more in detail in footnote 11, once I have introduced the electoral system). Parties and candidates do not make any strategic decision and the only players in the game are the two groups of voters. ${ }^{10}$

\footnotetext{
9 The system is used to elect the Spanish Senate, Gibraltar's House of Assembly and in some local-level elections in the United States.

10 When parties are not active players in the model, list length is an exogenous parameter. Here, I am fixing it to $S$, to allow both parties to contain "enough" candidates of each type in their lists. I believe any other choice would be as arbitrary as this one, but probably harder to justify. One option could be to assume that
} 
Under open list PR, each voter must (i) vote for a party and (ii) express up to $\pi \in\{1, \ldots, S\}$ preferential votes for candidates within its list. Voters cannot cast more than one preferential vote per candidate and cannot vote for candidates outside the party list they voted for. I assume groups act as unique and cohesive players. More precisely, each group $j \in\{m, M\}$ must decide (i) an assignment of votes $v_{j}^{P}$ to each party $P \in\{A, B\}$, such that $v_{j}^{A}+v_{j}^{B}=V_{j}$ and (ii) for each of the $v_{j}^{P}$ voters of group $j$ voting for party $P$, an allocation of (up to) $\pi$ preferential votes across the $S$ candidates in $P$, satisfying the property that no voter casts more than one vote for the same candidate.

The final composition of the parliament is then determined in two steps. First, seats are assigned to parties in proportion to the votes received. Given the amount of votes $v_{m}^{P}$ and $v_{M}^{P}$ assigned by each group to party $P$, the party wins $S^{P}=v_{m}^{P}+v_{M}^{P}$ seats $^{11}$. In the second step, the $S^{P}$ seats won by party $P$ are assigned to the candidates (in $P$ 's list) that have obtained the largest number of preferential votes. Ties are broken by assigning the seat to each entitled candidate with equal probability.

The groups care about the final composition of the parliament and want to maximize the number of candidates representing their interests. Let $C_{m}$ denote the set of all minority candidates running for election (with $\left|C_{m}\right|=2 V_{m}$ ) and by $W$ the set of elected candidates (with $|W|=S$ ). The set of elected minority candidates is therefore $W_{m}=C_{m} \cap W$. I define minority representation $(M R)$ as the cardinality of this set: $M R=\left|W_{m}\right|$. I say that minority representation is (perfectly) proportional, or that the minority is perfectly represented, whenever $M R=V_{m}$. Groups' preferences can be expressed as

$$
\begin{aligned}
U_{m} & =M R \\
U_{M} & =S-M R
\end{aligned}
$$

\section{Results}

As a preliminary observation, notice that it is a weakly dominated strategy for a group to vote for candidates representing the other group. For any strategy played by the majority, voting for a majority candidate either has no effect on the number of minority candidates elected, or it strictly decreases it. The symmetric reasoning holds for the majority. In the analysis that follows, I do not consider this type of strategies.

The following lemma contains a first, important observation about open list PR.

Lemma 1 In open list $P R$, receiving $\pi$ votes is a sufficient condition for a candidate to be elected.

\footnotetext{
Footnote 10 continued

one party contains exactly and only $V_{m}$ candidates. As I already argued in Sect. 1, however, this is not the right type of assumption in this setting. Furthermore, the existence of minority parties is hard to sustain in equilibrium when parties play a more active role (Sect. 4.1).

11 A more general formulation would assume that the total number of voters is $V>S$, that a party wins one seat every $q=V / S$ votes received and that unallocated seats are distributed to the party with the largest remainder (Largest Remainder Method). Setting $V=S$ allows to disregard remainders and is equivalent to assuming that each of the $V$ voters represents a group of $q$ individuals.
} 
A formal proof of the lemma is contained in the Appendix. Intuitively, as there are $V$ party-votes and $\pi$ preferential votes per voter, a total of $\pi V$ preferential votes will be cast. As $S=V$, winning $\pi$ preferential votes directly implies that a candidate wins a seat. $^{12}$

A direct consequence of Lemma 1 is that perfectly proportional minority representation is guaranteed whenever $\pi \leq V_{m}$. When $\pi$ is in this range, indeed, the minority is always able to assign $\pi$ preferential votes to $V_{m}$ candidates within the same party. Clearly, since $\pi \leq V_{m}$ implies $\pi \leq V_{M}$, an identical reasoning proves that the majority can always guarantee the election of $V_{M}$ majority candidates. The number of elected minority candidates therefore never exceeds the perfectly proportional one.

Proposition 1 In open list PR, the minority is proportionally represented in parliament $\left(M R=V_{m}\right)$ whenever $\pi \leq V_{m}$.

The outcome described in Proposition 1 can arise from multiple equilibria. In particular, all mixed strategy profiles where group $j \in\{m, M\}$ assigns all its votes to one party with probability $p_{j}$ are (outcome-equivalent) equilibria of the game. Extreme cases include those where $p_{j}=1$ or $p_{j}=0$ for both groups (one party winning all the votes), and those where $p_{j}=1$ and $p_{j^{\prime}}=0$ (each party receiving all and only the votes of one group). More refined mixed strategy profiles (for example, completely mixed ones) can constitute equilibria as long as they guarantee that $V_{m}$ minority candidates and $V_{M}$ majority ones are elected in expectations. This strictly depends on the assumptions about the size of the two groups and the value of $\pi$.

Let me now turn to the case of $\pi>V_{m}$. A first, immediate observation is that increasing the number of preferential votes can never improve the representation of the minority in parliament. As before, the majority can always guarantee the election of at least $V_{M}$ candidates, limiting the maximum number of elected minority candidates to $V_{m}$. When $\pi \in\left\{V_{m}, \ldots, V_{M}\right\}$, the result follows immediately from Lemma 1 , as discussed above. When $\pi>V_{M}$, by voting for exactly the same $V_{M}$ candidates, the majority can assign $V_{M}$ preferential votes to each of them, which is more than what any minority candidate can receive. This ensures the election of $V_{M}$ majority candidates.

As a matter of fact, the minority is strictly harmed by an increase in the number of preferential votes. Consider the following example.

Example 1 Let $V_{m}=1$ and $V_{M}=4$. When $\pi=1$, Proposition 1 guarantees $M R=1$. Now let $\pi=3$ and consider the following voting behavior by the majority: (i) partyvotes are equally divided between $A$ and $B\left(v_{M}^{A}=v_{M}^{B}=2\right)$ and (ii) for every party $P$, the 2 voters voting for it cast their preferential votes for the same three majority candidates. Figure 1 provides a graphical illustration. The strategy guarantees that three majority candidates in each party receive two preferential votes. Now consider the best response by the minority voter. Assume he votes for party $A$ and assigns his preferential vote to the only minority candidate in the party. Then, $A$ wins $S^{A}=3$ seats, and these will be assigned to the 3 candidates receiving the most preferential votes. These are all majority candidates. As the same conclusion holds if the minority voter votes for $B$, no minority candidate will be elected in equilibrium.

$\overline{12}$ I thank an anonymous referee for this simple and intuitive version of the proof. 

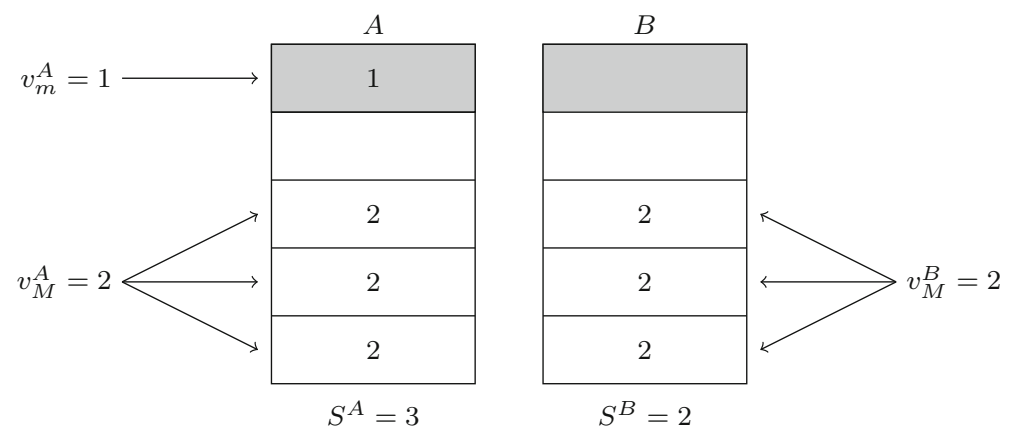

Fig. 1 Graphical representation of Example 1. The two columns represent party $A$ 's and $B$ 's lists. Each of the small rectangles represents a candidate, with minority candidates shaded in gray. On the side of each party list, I report the number of voters voting for it: party $A$ receives votes from two majority voters and one minority voter, party $B$ only receives two votes from the majority. When $\pi=3$, each of the majority voters can vote for three candidates, so that both $A$ and $B$ will contain three majority candidates receiving two preferential votes (the number of votes received by each candidate is marked inside the corresponding rectangle). If the minority voter votes for party $A$, the three seats won by the party will be won by majority candidates

Proposition 2 Let $V_{M}=2\left(V_{m}+1\right)$. In open list $P R$, minority representation is decreasing in $\pi$ whenever $\pi>V_{m}$. More precisely,

$$
M R(\pi) \leq \max \left\{V_{m}-\left(\pi-V_{M} / 2\right), 0\right\} .
$$

Inequality (1) generalizes the intuition behind Example 1: (the upper bound for) minority representation decreases (with respect to its perfectly proportional level, $V_{m}$ ) when the majority can vote for a number of candidates strictly larger than the number of seats it assigns to parties by equally splitting its votes between them, i.e. $\pi>V_{M} / 2$.

As for Proposition 1, there are many strategy profiles leading to the equilibrium outcome described in Proposition 2. The equilibrium strategy of the majority in this case is however fixed: the group must assign exactly half of the votes to each of the parties. Failing to do so would result in a positive probability that a minority candidate is elected. The multiplicity of equilibria then arises from the behavior of the minority. As before, assigning all the votes to one party with probability $p_{m}$ is an equilibrium strategy, for all $p_{m} \in[0,1]$.

Proposition 2 considers a specific size for the two groups. The case of a larger relative size of the majority $\left(V_{M}>2\left(V_{m}+1\right)\right)$ is of limited interest: it seems clear that, in this case, minority representation would decrease even faster when $\pi$ increases. A more interesting case is the one of a relatively small majority, $V_{M}<2\left(V_{m}+1\right)$. Consider a modified version of Example 1.

Example 2 Let $V_{m}=1, V_{M}=3$ and $\pi=3$. This is illustrated in Fig. 2. Assume the minority voter votes for party $A$ and assigns his preferential vote to the minority candidate in the party. The best response of the majority is to allocate two votes to $A$ and one to $B\left(v_{M}^{A}=2, v_{M}^{B}=1\right)$. Indeed, if the two voters voting for $A$ distribute their preferential votes across the same three candidates, these will be the only winners of the $S^{A}=3$ seats obtained by the party. In party $B$, three majority candidates receive 


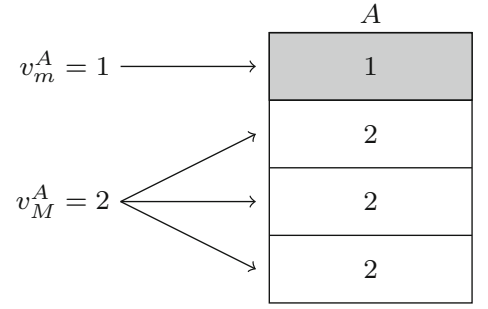

$S^{A}=3$

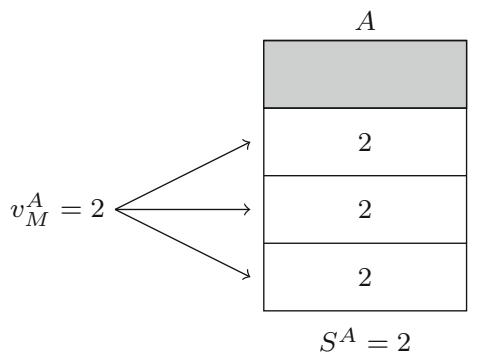

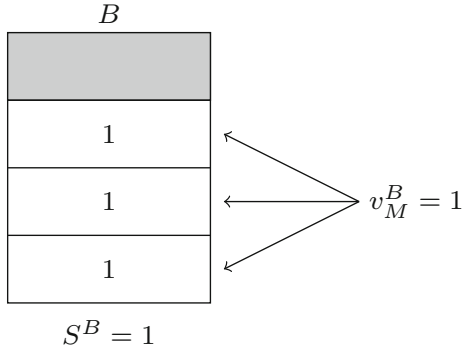

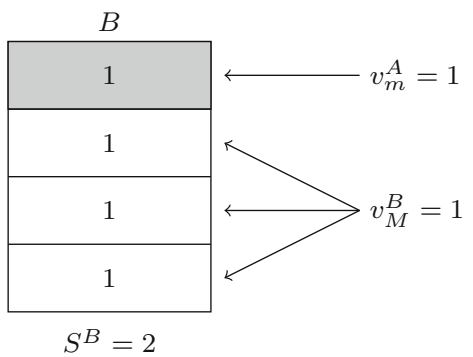

Fig. 2 Graphical representation of Example 2. If the minority assigns its vote to party $A$ (top figure), the best response by the majority is to assign two votes to $A$ and one to $B$ and let the two $A$-voters vote for the three majority candidates. However, given this strategy by the majority, the best response by the minority is to assign its vote to $B$ (bottom figure)

one preferential vote and each of them will be elected with probability $1 / 3$. Under this strategy profile then, $M R=0$. However, it cannot be an equilibrium. Given the strategy played by the majority, the minority voter strictly prefers to vote for $B$ : this allows the minority candidate in the party to receive one preferential vote and to compete with the other three majority candidates for the assignment of two seats. Thus, a minority candidate will be elected with probability $1 / 2$. The absence of an equilibrium in pure strategies now becomes evident: if the minority voter votes for $B$, the majority prefers a strategy that is symmetric to the one described before $\left(v_{M}^{A}=1, v_{M}^{B}=2\right)$, to which the minority voter would in turn best respond by voting for $A$. The (mixed strategy) equilibrium of the game involves the two players randomizing between their two strategies with equal probability, and leads to an outcome where a minority candidate is elected with probability 0.25 .

Proposition 3 In open list $P R$, minority representation is weakly decreasing in $\pi$ whenever $\pi>V_{m}$ and $V_{M}<2\left(V_{m}+1\right)$. More precisely,

- If $V_{M}=2 V_{m}+1$, then

$$
E[M R(\pi)]=\frac{1}{2}\left(2 V_{m}+1-\min \left\{\pi, V_{M}\right\}\right)+\frac{V_{m}^{2}}{V_{m}+\min \left\{\pi, V_{M}\right\}}
$$


- If $V_{M}<2 V_{m}+1$, then

$$
E[M R(\pi)]=\frac{1}{2}\left(3 V_{m}+1-\min \left\{\pi, V_{M}\right\}\right)
$$

where $E[M R(\pi)]$ denotes the equilibrium expected minority representation.

The qualitative result found in Proposition 2 therefore does not change: increasing the number of preferential votes goes against the interest of the minority. However, (expected) minority representation never reaches zero. When $\pi \geq V_{M}$, (2) and (3) become

$$
\begin{gathered}
E\left[M R\left(V_{M}\right)\right]=\frac{V_{m}^{2}}{3 V_{m}+1}>0 \\
E\left[M R\left(V_{M}\right)\right]=\frac{1}{2}\left(3 V_{m}+1-V_{M}\right)>0
\end{gathered}
$$

respectively. As one would expect, minority representation is decreasing in the relative size of the majority. Using ( $\left.3^{\prime}\right)$, one can see that $E\left[M R\left(V_{M}\right)\right]=V_{m}$ when $V_{M}=V_{m}+$ 1. At the opposite extreme, when $V_{M}=2 V_{m}+1,\left(2^{\prime}\right)$ implies that $E\left[M R\left(V_{M}\right)\right]<$ $V_{m} / 3$.

\section{Extensions}

\subsection{Endogenous party list composition}

Assume the number of minority candidates in each list is not set by law and parties are free to decide list composition. This introduces two new players in the game, (the leader of) party $A$ and (the leader of) party $B$. Assume their only goal is to maximize the number of seats won. A first, natural question to ask is whether the list composition I assumed in the benchmark model can be sustained in equilibrium. For simplicity, let me assume that party leaders can only decide whether to include $V_{m}$ minority candidates or not in their lists. ${ }^{13}$ Also, let me focus on the two polar cases of $\pi \leq V_{m}$ and $\pi=S$. Considering more refined strategies and intermediate values of $\pi$ would consistently decrease the tractability of the analysis and conclusions would very likely depend on specific assumptions on the size of the two groups.

Assume both party lists initially contain $V_{m}$ minority candidates and let $\pi \leq V_{m}$. As noted above, many voting equilibria can arise in this subgame. While they all lead to the same outcome in terms of minority representation, they differ in the number of seats obtained by each party. Equilibrium restrictions in the voting subgame therefore matter a lot for the conclusions. The same holds for equilibrium outcomes in the subgame

\footnotetext{
13 Parties cannot choose list length. When candidates can be placed on lists at no cost, the assumption is not very restrictive, as there is no situation in which a party could benefit by reducing the number of candidates it includes in its list.
} 
where only one party contains minority candidates. In general, one can always find conditions on voting behavior that ensure the existence of equilibria with both parties containing minority candidates. However, this type of equilibrium fails to exist under reasonable assumptions. For example, assume that, if only one party contains majority candidates, it obtains all the votes of the majority. This is the case if, everything else being equal, the group prefers to vote for the party that "best represents" its interests. Then, (at least) one party has incentives to replace the $V_{m}$ minority candidates with majority ones.

Now assume $\pi=S$. Even if one party removes the $V_{m}$ minority candidates, it will never be able to attract all the votes of the majority. The minority will vote for the other party and, in turn, this will attract some of the votes of the majority (exactly half in the case of Proposition 2), who aims at preventing the election of minority candidates in the party. The deviating party therefore strictly decreases the number of seats won. The existence of equilibria where both parties contain $V_{m}$ candidates in their lists is therefore easier to sustain when $\pi$ is large.

The opposite question one can ask is whether equilibria where no party contains minority candidates can exist. In line with the intuition above, this is more likely for small values of $\pi$ (although, as before, this type of equilibria do not exist under specific restrictions on voting behavior). Sufficient conditions for the existence of an equilibrium with no minority candidates in party lists are that (i) equilibrium behavior in this subgame results in both parties obtaining half of the seats and (ii) the majority casts all its votes for one party whenever this is the only party containing majority candidates. Under these assumptions, no party would be willing to include a minority candidate in its lists when the other does not. The opposite holds when $\pi$ is large and the intuition is the same as before: attracting the votes of the minority helps to attract the votes of the majority too.

Combined together, the answers to the two questions show that incentives to include minority candidates in party lists are stronger when $\pi$ is large. This is somewhat surprising. Given the results in Sect. 3, one would expect these incentives to be stronger for small values of $\pi$. If the minority can guarantee the election of some candidates with their votes, parties should be more likely to target the group. These incentives look much weaker for the case of large $\pi$, where the power of the minority is consistently reduced. As it turns out, this intuition is misleading. The willingness of the majority to prevent the election of minority candidates acts as a powerful force and induces parties to include (some) minority candidates in their lists.

Finally, this simple framework can be used to answer an additional question: can there be equilibria with one "minority party"? This would be a situation where only one party contains minority candidates. Let this party be $A$. There are two possible reasons why this configuration might not be part of an equilibrium. First, party $A$ might have incentives to replace the minority candidates with majority ones. Second, party $B$ might want to add minority candidates in its list. For $\pi \leq V_{m}$, the profitability of the two deviations depends, again, on equilibrium restrictions in the voting subgames. Just consider the following two examples. First, let the majority vote for party $B$ (the "fully majoritarian" party), so that party $A$ obtains only $V_{m}$ seats. Also, assume that when no party contains minority candidates, each of them gets half of the votes. In this case, party $A$ can profitably deviate by replacing the minority candidates with 
majority ones. Alternatively, assume the majority votes for $A$ as well and the party obtains more than half of the seats. Then party $B$ might have incentives to include $V_{m}$ candidates in its list too. This is a profitable deviation if, among the equilibria arising in a voting subgame where both parties contain $V_{m}$ minority candidates, one selects those in which seats are equally shared.

When $\pi$ is large, a "minority party" can never exist. The driving forces are the same as before: (both) parties need minority candidates to attract the votes of the majority. If only party $A$ contains minority candidates, it will obtain the votes of the minority and many votes of the majority. Party $B$ has therefore incentives to include some minority candidates in its list, to attract the votes of the two groups.

As a side note, notice that this reasoning rules out the existence of "pure minority parties", i.e. those containing exactly and only $V_{m}$ minority candidates. For party $A$ in the example, including majority candidates in the list strictly increases the number of seats won, as it allows to attract more votes from the majority. A pure minority party could only exist in my model if parties were not purely interested in maximizing the number of seats won.

The simple framework considered here clearly does not claim to be an exhaustive description of party behavior under open list PR. However, it suggests an interesting conclusion: imposing a quota on the number of minority candidates that must appear on party lists can only help the interest of the minority. When $\pi$ is small, party decisions are likely to reduce minority representation, by reducing the availability of minority candidates in their lists. On the contrary, parties seem to have larger incentives to include minority candidates when $\pi$ is large. Given the conclusions obtained in the previous section, however, the minority is never able to benefit from it. Notice that this reinforces the conclusions obtained in the previous section: at the constitutional stage during a transitions to democracy, a majority ethnic group in an ethnically divided society may have incentives to choose open list PR with large $\pi$.

\subsection{Number of parties}

Proportional representation systems are usually associated with the existence of multiple parties. The results contained in Lemma 1 and, as a consequence, in Proposition 1 are independent of the number of parties one considers (as long as list composition is decided by the law as in the baseline model). The presence of more than two parties would definitely enlarge the set of equilibria having $M R=V_{m}$ as an outcome, but would not limit the ability of the minority to ensure the election of their favorite candidates.

The conclusions in Proposition 2 hinge on the possibility for the majority to assign a large number of votes to all parties. In presence of more than two parties, therefore, the relative size of the majority should be even larger for the result to hold. If, for example, the number of parties was equal to three, the intuition behind Proposition 2 would still hold if $V_{M} \geq 3\left(V_{m}+1\right)$ : the majority could assign $V_{m}+1$ votes to each of the three parties and, as $\pi$ increases, cast a large number of preferential votes to more and more candidates. More generally, a sufficient condition for the equivalent of Proposition 2 to hold in presence of $N>2$ parties is that $V_{M} \geq N\left(V_{m}+1\right)$. 
Proposition 4 Assume there are $N>2$ parties in the country. When $\pi>V_{m}$, $V_{M} \geq N\left(V_{m}+1\right)$ is a sufficient condition to have

$$
M R(\pi) \leq \max \left\{V_{m}-\left(\pi-V_{M} / N\right), 0\right\}
$$

For a fixed size of the majority, then, a larger number of parties makes it more difficult for the group to prevent the election of minority candidates. Given that PR systems are typically associated with the existence of many parties, this partially mitigates the negative results obtained in the previous sections.

The case of a "small" majority (Proposition 3) is not as straightforward to analyze and I can only formulate conjectures about it. As before, the majority wants to concentrate enough votes on the party chosen by the minority, while the minority will try to differentiate its vote as much as possible from the one of majority. The equilibrium will be in mixed strategies. For some combinations of the pure strategies played with positive probability in equilibrium, the two groups will vote for different parties and some minority candidates will be elected. For some other combinations instead, the majority will concentrate enough votes on the party the minority is voting for and will be able to prevent the election of (some) minority candidates. The larger $\pi$, the lower the number of minority candidates elected in this scenario. Expected minority representation is probably increasing in the number of parties, as this increases the opportunity for the minority to vote for a different party than the majority. However, for a fixed number of parties, the comparative statics on $\pi$ should not change.

\section{Limited vote versus open list PR}

As discussed in Sect. 1, an increase in the number of preferential votes produces the same effect under limited vote and open list PR. This section highlights the differences between the two systems. The possibility to cast a party-vote under open list PR turns out to play a fundamental role.

When $\pi$ is small, the election of minority candidates is guaranteed under both systems. Similarly, when $\pi$ is very large and the two groups consistently differ in their sizes (as in Proposition 2), no systems will guarantee any positive level of minority representation. However, in presence of a "small" majority (as in Proposition 3), the two systems produce substantial differences when many preferential votes can be expressed.

Consider Example 2 again. Under open list PR, a minority candidate wins a seat with probability 0.25 . Now assume the eight candidates in the two parties compete under limited vote. Voters face a ballot containing two minority candidates and six majority ones and must cast a preferential vote for three of them. If majority voters assign their votes to the same four majority candidates, these will receive (at least) two votes each. As minority candidates can receive at most one vote, none of them has a positive probability of being elected. Thus, minority representation would be zero under limited vote.

The presence or absence of party lists is therefore key. Under open list PR, candidates are divided in two groups that only partially compete against each other. The 
election of a minority candidate in one party is independent of the number of preferential votes obtained by majority candidates in the other. In order to completely prevent the election of minority candidates, then, the majority should be able to assign enough votes to its favorite candidates in both lists. This imposes stronger constraints on the size of the majority than those imposed by limited vote.

Open list PR also produces different incentives for parties to include minority candidates in their lists. In Sect. 4.1, I discussed how a situation where no party contains minority candidates is very unlikely to occur under open list PR with large $\pi$. In addition, whenever a party contains some minority candidates, the other party has incentives to include some too. The same is not true under limited vote. Again, Example 2 provides a good intuition. For open list PR, assume party $B$ does not contain any minority candidate in its list. Then, by including one minority candidate, party $A$ can attract the votes of the minority and two votes by the majority. This is because by setting $v_{M}^{A}=2$, the majority can assign two preferential votes to three candidates, preventing the election of the minority one. Thus, party $A$ strictly benefits from introducing the minority candidate in its list. Now consider the equivalent situation under limited vote. Assume all of the eight candidates on the ballot are majority candidates. Would a party be able to increase the number of seats won by replacing some of those candidates with minority ones? As long as at least four majority candidates remain on the ballot, no minority candidate would have any chance of being elected. Then, a party can never gain by including more minority candidates.

Combining the two insights, one can conclude that open list PR performs relatively better than limited vote in protecting the interest of the minority. The two systems produce equivalent results for extreme cases (small $\pi$ or large $\pi$ with large majority). However, open list PR guarantees a positive expected minority representation for smaller sizes of the majority and creates higher incentives for parties to include minority candidates in their lists.

\section{Discussion}

\subsection{Coordination}

As noted in Sect. 1, the paper makes a list of assumptions guaranteeing a highly coordinated and cohesive behavior by the two groups. This section explores the consequences of assuming lower degrees of coordination. If the minority did not behave as cohesive group, it would only decrease its chances to elect representatives that act in its interest. This would only reinforce my conclusions on the limited ability of open list PR to protect minority interests.

A less cohesive majority would probably increase the chances of electing minority candidates. However, the comparative static results on the effect of $\pi$ would not change. The key intuition is the following: a less coordinated majority would have lower chances of being able to target its votes to the same party the minority voted for. This would therefore reduce the ability to prevent the election of minority candidates. However, with strictly positive probability, the majority will still assign enough votes to the same party supported by the minority. Increases in $\pi$ reduce the probability that 
a minority candidate is elected in those scenarios, therefore reducing overall minority representation. The following illustrative example assumes no coordination power for the majority and a completely non-strategic behavior by voters within it. It shows that, even in this limit case, (expected) minority representation is decreasing in $\pi$.

Example 3 Let $V_{m}=1$ and $V_{M}=3$. Assume the majority does not act as a cohesive group and each voter in the group behaves completely non-strategically. More precisely, let each of them vote for party $A$ with probability $\rho$. Furthermore, assume they distribute their preferential votes randomly across majority candidates in the party they voted for. ${ }^{14}$ The minority is still assumed to be a cohesive and strategic group, as in the benchmark model. Without loss of generality, let the minority voter vote for party $A$ and for the minority candidate in its list. When $\pi=1$, the candidate is elected for sure by Lemma 1 . When $\pi=2$, the probability that the candidate is elected depends on how many majority voters vote for party $A$ and on how they distribute their preferential votes. If no majority voter votes for $A$ or if all of them do, the minority candidate is elected for sure. If only one majority voter votes for $A$, the candidate is elected with probability 2/3: party $A$ wins two seats and contains three candidates (the minority candidate and two majority ones) receiving one preferential vote. If two majority candidates vote for $A$, they can distribute their preferential votes in two possible ways: with probability $1 / 3$, they give two preferential votes to two majority candidates and none to the third; with probability $2 / 3$, they give two votes to one candidate and one to the other two. In the first case, the minority candidate is elected for sure. In the second, she is elected with probability $1 / 3$. Combining all these considerations, expected minority representation for $\pi=2$ is

$$
E[M R(2)]=\rho^{3}+(1-\rho)^{3}+\frac{2}{3}\left(\begin{array}{l}
3 \\
1
\end{array}\right) \rho(1-\rho)^{2}+\left(\begin{array}{l}
3 \\
2
\end{array}\right) \rho^{2}(1-\rho)\left(\frac{1}{3}+\frac{2}{3} \cdot \frac{1}{3}\right)
$$

Now assume $\pi=3$. As before, the minority candidate is elected for sure when no majority voter votes for $A$ or all of them do. When only one voter votes for $A$, the minority candidate wins with probability $1 / 2$ as she competes with three other candidates for the assignment of two seats. Finally, when two majority voters vote for $A$, they assign two preferential votes to all majority candidates in the party and the minority candidate has no chances of being elected. Expected minority representation in this case is then

$$
E[M R(3)]=(1-\rho)^{3}+\frac{1}{2}\left(\begin{array}{l}
3 \\
2
\end{array}\right) \rho(1-\rho)^{2}+\rho^{3}
$$

It is immediate to see that $E[M R(1)]>E[M R(2)]>E[M R(3)]$.

\footnotetext{
14 In the example, voters are still perfectly able to distinguish minority from majority candidates. Relaxing this assumption would considerably complicate the analysis, as it would require to consider all the possible combinations of preferential votes that a group of majority voters can cast for candidates in a party. As long as majority voters can distinguish majority candidates with sufficiently high probability, however, the conclusions would not change.
} 
Table 1 Distribution of individuals across class- and ethnic-identity

\begin{tabular}{lll}
\hline & $M$ & $m$ \\
\hline$r$ & 1 & 1 \\
$p$ & 5 & 1 \\
\hline
\end{tabular}

\subsection{Ethnic politics versus class politics}

Consider again the ethnic politics versus class politics dilemma discussed in Sect. 1. In this section, I discuss how my model can be applied to a society that is divided along both dimensions. I provide an example inspired by Huber (2017). Individuals in the society have two "identities": a class-identity, referring to their income level, and an ethnic-identity. Assume there are two possible class-identities, rich $(r)$ and poor $(p)$, and two possible ethnic-identities, majority $(M)$ and minority $(m)$. This defines four possible groups: the rich majority, the rich minority, the poor majority and the poor minority. Table 1 shows an hypothetical distribution of eight voters across the different identities. Rows represent class-identity, columns represent ethnic-identity. Each cell in the table then contains the number of individuals belonging to each of the four groups.

There exist two parties, the party of the rich $(R)$ and the one of the poor $(P)$. Each party also contains two minority candidates and six majority ones. The electoral system is open list PR, exactly as in the baseline model. Assume voters care about two goals: (i) they want the party representing their class-identity to win the majority of the seats in parliament; and (ii) they want to maximize the number of elected candidates representing their ethnic-identity. Assume also that voters in the poor majority group are perfectly able to coordinate. In this scenario, what would be the voting equilibrium for different values of $\pi$ ?

Start by considering $\pi \leq 2$. If one focuses only on strategies that are not weakly dominated, voting according to class-identity (i.e. all the rich voting for party $R$ and all the poor voting for party $P$ ) is the only equilibrium in this case. Party $P$ wins the majority of the seats (6) and two minority candidates are elected, one in each party. No voter has an incentive to change voting behavior: they are all voting for their favorite party and no deviation can increase the number of elected candidates representing an ethnic group. ${ }^{15}$

Now assume $\pi=8$. If voters purely voted according to their class-identity, as in the equilibrium just described, no minority candidate would be elected in party $P$ : the poor majority group would be able to assign five preferential votes to all the majority candidates in the party. In party $R$, the two minority candidates would compete with the majority candidates for the assignment of two seats. A minority candidate would be elected with probability $1 / 4$. In this scenario, the poor minority voter would prefer to vote "ethnically" for party $R$. This would not affect the chances of party $P$ winning the majority of seats, but would guarantee the election of two minority candidates

15 If weakly dominated strategies are allowed, the strategy profile such that all minority voters vote for party $R$ and all majority voters vote for party $P$ is also an equilibrium. As in the baseline model, the two equilibria are outcome-equivalent in terms of minority representation. 
in party $R$. A similar reasoning shows that a pure "ethnic-voting" equilibrium might not exist when ethnic considerations are strong enough. Assume all minority voters vote for party $R$ and all majority voters vote for party $P$. The outcome would be the same as for the case of small $\pi$ : party $P$ would win the majority of the seats and two minority candidates would be elected in party $R$. In this scenario, the poor minority group might prefer to assign two votes to party $R$ : this would make the two parties tie, but would strictly decrease the number of elected minority candidates. If ethnicpolitics dominates class-politics, this a profitable deviation. Under similar conditions, the equilibrium in this voting game is such that all voters vote for their favorite party, except for two poor-majority voters, who vote for party $R$ (or, in other words, the majority equally splits its votes across the two parties). This creates a tie between the two parties but prevents the election of any minority candidate.

The example perfectly replicates the results contained in the main section of the paper. Under open list PR with small $\pi$, the interest of the minority are always protected, even if voters vote according to their class-identity. When $\pi$ is large however, a stronger ethnic-identity would induce the majority to disregard class interests and optimally distribute its votes across different parties, in order to limit the representation of minorities. This conclusion is of particular relevance if one considers the constitutional stage in a democratizing country. A class-based ruling majority would prefer to adopt an open list PR with small $\pi$. However, an ethnic-based ruling majority will always set $\pi$ very large: whenever ethnic-identity is predominant in the society, this allows the group to consistently limit the representation of minorities in parliament.

\section{Conclusions}

The paper contributes to the literature on the impact of electoral systems on minority representation. In particular, it studies the relationship between the number of candidates voters can vote for under open list PR and the representation of minorities in parliament. I consider a society divided in two groups, whose goal is to elect as many candidates representing their interests as possible. Voters can vote for a party and, within the party, can express some preferential votes for individual candidates. Seats are first allocated across parties in proportion to the votes received and then within parties to the candidates obtaining the largest number of preferential votes.

My results show that an increase in the number of preferential votes that can be cast by voters reduces the representation of minorities in parliament. This is because of a multiplier effect: when more preferential votes are allowed for each individual, the total number of votes the majority can use increases more than the one for the minority. Thus, the majority can always assign more votes to more candidates.

Most of the assumptions made in the model are conservative ones. They allow for a clean and simple analysis of a situation where minorities are unable to create their own parties. The groups must therefore rely on the possibility to elect candidates representing their interests in parties containing many other different candidates. This is the only situation in which the number of preferential votes to be expressed matters for minority representation. Results show how this can be very limited even in the 
most favorable situation for the minority. Relaxing many of the assumptions I make would therefore only worsen the outcome.

The result of the paper is in line with what was already proven for limited vote systems. However, the possibility to cast a party-vote under open list PR turns out to have a significant impact. More precisely, minority representation seems to be (relatively) better protected under open list PR. This is because the system limits the power of the majority to prevent the election of minority candidates and provides higher incentives to parties to let minority candidates run.

An interesting application of the model helps drawing conclusions on the design of electoral systems in countries that are transitioning to democracy. When the ethnic division in a society is particularly strong, majority ethnic groups prefer to allow many preferential votes to be expressed. This helps the groups to reduce the power of opposing minorities.

Acknowledgements I am extremely grateful to Massimo Morelli and François Maniquet for their precious help on this project. I would also like to thank the participants to the SAET Conference 2013, the Political Economy Breakfast at Columbia University, the Graduate Political Economy seminar at Princeton University and the LSE Workshop on Positive Theory and Comparative Politics. I am grateful to FNRS for their financial support. Finally, I thank the editor Maggie Penn and two anonymous referees for their useful comments.

Open Access This article is distributed under the terms of the Creative Commons Attribution 4.0 International License (http://creativecommons.org/licenses/by/4.0/), which permits unrestricted use, distribution, and reproduction in any medium, provided you give appropriate credit to the original author(s) and the source, provide a link to the Creative Commons license, and indicate if changes were made.

\section{Appendix}

Proof of Lemma 1 Assume a candidate $c \in P$ receives $\pi$ preferential votes. Since no voter can cast more than one preferential vote for the same candidate, at least $\pi$ voters must be voting for $P$ and $S^{P} \geq \pi$. Candidate $c$ faces a positive probability of not being elected only if at least $S^{P}$ other candidates in party $P$ receive at least $\pi$ preferential votes. Thus, there must be at least $\pi+1$ candidates in $P$ receiving at least $\pi$ votes. As no voter can vote for more than $\pi$ candidates, this is only possible if at least $\pi+1$ voters vote for $P$. Thus, $S^{P} \geq \pi+1$. Candidate $c$ then faces a positive probability of not being elected only if there are at least $\pi+1$ other candidates receiving at least $\pi$ votes. Then, at least $\pi+2$ candidates in $P$ must be receiving at least $\pi$ votes. By the same reasoning used before, this implies that at least $\pi+2$ individuals must be voting for $P$ and $S^{P} \geq \pi+2$. Applying the same reasoning enough times, one finds that $c$ 's probability of not being elected is strictly positive only if $S^{P} \geq S$, a contradiction.

Proof of Proposition 2 Assume the majority plays the following strategy: (i) $v_{M}^{A}=$ $v_{M}^{B}=V_{M} / 2$ and (ii) for each party $P$, the $v_{M}^{P}$ voters voting for it assign their preferential votes to the same $\min \left\{V_{M}, \pi\right\}$ candidates, where the minimum is introduced to exclude the possibility that majority voters vote for minority candidates when $\pi>V_{M}$. Each party therefore contains $\min \left\{V_{M}, \pi\right\}$ majority candidates receiving $V_{M} / 2=V_{m}+1$ preferential votes. This is more than what any minority candidate can 
obtain $\left(V_{m}\right)$. Consider any assignment of votes to parties by the minority $\left(v_{m}^{A}, v_{m}^{B}\right)$. Each party $P$ wins $S^{P}=V_{M} / 2+v_{m}^{P}$ seats, and the number of elected majority candidates in the party will be $\min \left\{S^{P}, V_{M}, \pi\right\}=\min \left\{S^{P}, \pi\right\}$, since $S^{P}<V_{M}$. Minority candidates will win any residual seat, so that

$$
M R=S-\min \left\{S^{A}, \pi\right\}-\min \left\{S^{B}, \pi\right\}
$$

To complete the proof, it remains to be proven that

$$
S-\min \left\{S^{A}, \pi\right\}-\min \left\{S^{B}, \pi\right\} \leq \max \left\{V_{m}-\left(\pi-V_{M} / 2\right), 0\right\}
$$

Notice that, if $\pi \geq \max \left\{S^{A}, S^{B}\right\}$,

$$
S-\min \left\{S^{A}, \pi\right\}-\min \left\{S^{B}, \pi\right\}=S-S^{A}-S^{B}=0
$$

and (6) is always satisfied. If $\pi \leq \min \left\{S^{A}, S^{B}\right\}$, then

$$
S-\min \left\{S^{A}, \pi\right\}-\min \left\{S^{B}, \pi\right\}=S-2 \pi \leq V_{m}-\left(\pi-V_{M} / 2\right)
$$

whenever $\pi \geq V_{M} / 2=V_{m}+1$. Finally, if $S^{P}<\pi<S^{P^{\prime}}$,

$$
S-\min \left\{S^{A}, \pi\right\}-\min \left\{S^{B}, \pi\right\}=S-S^{P}-\pi \leq V_{m}-\left(\pi-V_{M} / 2\right)
$$

since $S^{P} \geq V_{M} / 2$ by definition.

Proof of Proposition 3 First of all, notice that the only rationalizable strategies for the minority must be such that $v_{m}^{P}=V_{m}$ and $v_{m}^{P^{\prime}}=0$ for some $P, P^{\prime} \in\{A, B\}$, $P \neq P^{\prime}$. If minority voters vote for all $V_{m}$ minority candidates in the party they have chosen, all these candidates will receive $V_{m}$ preferential votes. Once all nonrationalizable strategies by the minority have been eliminated, the majority is left with only two undominated strategies: assign $v_{M}^{P}=V_{m}+1$ votes to some party $P$ and $v_{M}^{P^{\prime}}=V_{M}-\left(V_{m}+1\right)$ votes to party $P^{\prime}$, and let majority voters vote for the same $\min \left\{\pi, V_{M}\right\}$ candidates in the two parties. Thus, only four possible strategy profiles can emerge. The outcomes originating from these strategies depend on the relative size of the majority. Let $V_{M}<2 V_{m}+1$. When $v_{m}^{P}=V_{m}, v_{m}^{P^{\prime}}=0$ and $v_{M}^{P}=V_{m}+1$, $v_{M}^{P^{\prime}}=V_{M}-\left(V_{m}+1\right), S^{P}=2 V_{m}+1$ and $S^{P^{\prime}}=V_{M}-\left(V_{m}+1\right)$. As majority candidates in $P$ have priority in the allocation of seats (each of them receives $V_{m}+1$ votes, while each minority candidate only receives $V_{m}$ ) and no minority candidate receives any preferential vote in party $P^{\prime}$, the number of elected minority candidates will be

$$
M R_{1}=S^{P}-\min \left\{\pi, V_{M}\right\}=2 V_{m}+1-\min \left\{\pi, V_{M}\right\}
$$

Now let $v_{m}^{P}=V_{m}, v_{m}^{P^{\prime}}=0$ and $v_{M}^{P}=V_{M}-\left(V_{m}+1\right), v_{M}^{P^{\prime}}=V_{m}+1$. Under my assumption on the relative size of the two groups, $V_{M}-\left(V_{m}+1\right)<V_{m}$ and minority candidates have priority in the allocation of the $S^{P}=V_{M}-1$ seats. All 
minority candidates will be therefore elected. The following table shows the payoffs originating from the four strategy profiles. The strategies for the minority are shown on the raws, those of the majority on the columns. The payoff for the minority is the first entry in the payoff vector. ${ }^{16}$

\begin{tabular}{c|c|c} 
& $\left(V_{m}+1, V_{M}-\left(V_{m}+1\right)\right)$ & $\left(V_{M}-\left(V_{m}+1\right), V_{m}+1\right)$ \\
\hline$\left(V_{m}, 0\right)$ & $M R_{1}, S-M R_{1}$ & $V_{m}, S-V_{m}$ \\
\hline$\left(0, V_{m}\right)$ & $V_{m}, S-V_{m}$ & $M R_{1}, S-M R_{1}$ \\
\hline
\end{tabular}

As this is a zero-sum game and $M R_{1}<V_{m}$, the only equilibrium is a mixed strategy profile where the groups play each of their pure strategies with equal probability. The expected minority representation originating from this equilibrium is then

$$
E[M R(\pi)]=\frac{1}{2} M R_{1}+\frac{1}{2} V_{m}=\frac{1}{2}\left(3 V_{m}+1-\min \left\{\pi, V_{M}\right\}\right)
$$

Now consider the case of $V_{M}=2 V_{m}+1$. The only change with respect to the previous case is that now, when $v_{m}^{P}=V_{m}, v_{m}^{P^{\prime}}=0$ and $v_{M}^{P}=V_{M}-\left(V_{m}+1\right), v_{M}^{P^{\prime}}=V_{m}+1$, minority and majority candidates in party $P$ receive the same amount of preferential votes. Thus, each of them wins one of the $S^{P}=2 V_{m}$ seats with equal probability and the expected number of elected minority candidates in this case is therefore

$$
M R_{2}=\frac{2 V_{m}}{V_{m}+\min \left\{\pi, V_{M}\right\}} V_{m}
$$

The modified payoff matrix is

\begin{tabular}{c|c|c} 
& $\left(V_{m}+1, V_{M}-\left(V_{m}+1\right)\right)$ & $\left(V_{M}-\left(V_{m}+1\right), V_{m}+1\right)$ \\
\hline$\left(V_{m}, 0\right)$ & $M R_{1}, S-M R_{1}$ & $M R_{2}, S-M R_{2}$ \\
\hline$\left(0, V_{m}\right)$ & $M R_{2}, S-M R_{2}$ & $M R_{1}, S-M R_{1}$ \\
\hline
\end{tabular}

As the mixed strategy equilibrium does not change, one obtains

$$
E[M R(\pi)]=\frac{1}{2}\left(2 V_{m}+1-\min \left\{\pi, V_{M}\right\}\right)+\frac{V_{m}^{2}}{V_{m}+\min \left\{\pi, V_{M}\right\}}
$$

Proof of Proposition 4: The proof mirrors the one for Proposition 2. Denote by $\mathcal{P}$ the set of parties in the country. Let $V_{M}=N\left(V_{m}+1\right)$ and assume the majority plays the following strategy: (i) $v_{M}^{P}=V_{M} / N$ for all $P \in \mathcal{P}$ and ii) for each party $P$, the $v_{M}^{P}$ voters voting for it assign their preferential votes to the same $\min \left\{V_{M}, \pi\right\}$ candidates. Each party therefore contains $\min \left\{V_{M}, \pi\right\}$ majority candidates receiving $V_{M} / N=V_{m}+1$ preferential votes. As in Proposition 2, consider any assignment of votes to parties by the minority $\left(v_{m}^{P}\right)_{P \in \mathcal{P}}$. Each party $P$ wins $S^{P}=V_{M} / N+v_{m}^{P}$ seats,

16 The underlying assumption is that the voters voting for a party assign their preferential votes to the same candidates and vote for as many candidates representing their group as possible. 
and the number of elected majority candidates in the party will be $\min \left\{S^{P}, V_{M}, \pi\right\}=$ $\min \left\{S^{P}, \pi\right\}$, since $S^{P}<V_{M}$. Minority candidates will win any residual seat, so that

$$
M R=S-\sum_{P \in \mathcal{P}} \min \left\{S^{P}, \pi\right\}
$$

It remains to be shown that the right hand side of (7) is always lower than $\max \left\{V_{m}-\right.$ $\left.\left(\pi-V_{M} / N\right), 0\right\}$. As in the proof of Proposition 2, whenever $\pi \geq \max _{P \in \mathcal{P}} S^{P}$,

$$
S-\sum_{P \in \mathcal{P}} \min \left\{S^{P}, \pi\right\}=0 \leq \max \left\{V_{m}-\left(\pi-V_{M} / N\right), 0\right\}
$$

while $\pi \leq \min _{P \in \mathcal{P}} S^{P}$

$$
S-\sum_{P \in \mathcal{P}} \min \left\{S^{P}, \pi\right\}=S-N \pi \leq \max \left\{V_{m}-\left(\pi-V_{M} / N\right), 0\right\}
$$

when $\pi \geq V_{M} / N=V_{m}+1$. Define the set $\tilde{\mathcal{P}} \subseteq \mathcal{P}$ as

$$
\tilde{\mathcal{P}}=\left\{P \in \mathcal{P} \mid S^{P} \geq \pi\right\}
$$

and denote by $|\tilde{\mathcal{P}}|$ its cardinality. When $\min _{P \in \mathcal{P}} S^{P}<\pi<\max _{P \in \mathcal{P}} S^{P}$,

$$
S-\sum_{P \in \mathcal{P}} \min \left\{S^{P}, \pi\right\}=S-\sum_{P \notin \tilde{\mathcal{P}}} S^{P}-|\tilde{\mathcal{P}}| \pi \leq V_{m}-\left(\pi-V_{M} / N\right)
$$

By adding and subtracting $V_{M}$, one can re-write

$$
V_{m}-\left(\pi-V_{M} / N\right)=S-\frac{(N-1) V_{M}}{N}-\pi
$$

Then

$$
S-\sum_{P \notin \tilde{\mathcal{P}}} S^{P}-|\tilde{\mathcal{P}}| \pi \leq S-\frac{(N-1) V_{M}}{N}-\pi
$$

since for all $P \notin \tilde{\mathcal{P}}, V_{M} / N \leq S^{P}<\pi$.

\section{References}

Ames B (1995) Electoral strategy under open-list proportional representation. Am J Polit Sci 39(2):406-433 Aumann RJ (1959) Acceptable points in general cooperative $n$-person games. In: Tucker AW, Luce RP (eds) Contributions to the theory of games IV. Princeton University Press, Princeton, pp 287-324

Carey JM, Shugart MS (1995) Incentives to cultivate a personal vote: a rank ordering of electoral formulas. Elect Stud 14(4):417-439 
Chang EC (2005) Electoral incentives for political corruption under open-list proportional representation. J Polit 67(3):716-730

Chang EC, Golden MA (2007) Electoral systems, district magnitude and corruption. J Polit Sci 37(1):115-37

Coate S, Conlin M (2004) A group rule-utilitarian approach to voter turnout: theory and evidence. Am Econ Rev 94(5):1476-1504

Feddersen T, Sandroni A (2006) A theory of participation in elections. Am Econ Rev 96(4):1271-1282

Huber J (2017) Exclusion by elections: inequality, ethnic diversity and redistribution. Cambridge University Press, Cambridge

Huber JD (2012) Measuring ethnic voting: do proportional electoral laws politicize ethnicity? Am J Polit Sci 56(4):986-1001

Lijphart A, Gibberd RW (1977) Thresholds and payoffs in list systems of proportional representation. Eur J Polit Res 5(3):219-244

Lijphart A, Pintor RL, Sone Y (1986) The limited vote and the single nontransferable vote: lessons from the Japanese and Spanish examples. In: Grofman B, Lijphart A (eds) Electoral laws and their political consequences. Agathon, New York

Pitkin HF (1967) The concept of representation. University of California Press, Berkeley

Rae D, Hanby V, Loosemore J (1971) Thresholds of representation and thresholds of exclusion. Comp Polit Stud 3(4):479-488

Shugart MS, Valdini ME, Suominen K (2005) Looking for locals: voter information demands and personal vote-earning attributes of legislators under proportional representation. Am J Polit Sci 49(2):437-449

Taagepera R (1998) Nationwide inclusion and exclusion thresholds of representation. Elect Stud 17(4):405417 